Multidisciplinary

SCIENTIFIC JOURNAL OF MARITIME RESEARCH

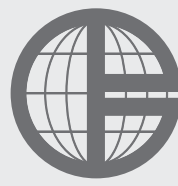

University of Rijeka

Faculty of Maritime

Studies Rijeka
Multidisciplinarni

znanstveni časopis

POMORSTVO

\title{
Analysis of advantages and disadvantages of existing maritime communication systems for data exchange
}

\author{
Sanjin Valčić ${ }^{1}$, Zoran Mrak ${ }^{1}$, Marko Gulić ${ }^{1}$ \\ ${ }^{1}$ University of Rijeka, Faculty of Maritime Studies Rijeka, Studentska 2, 51000 Rijeka, Croatia, e-mail: svalcic@pfri.hr
}

\begin{abstract}
Maritime communication systems and devices that are required onboard ships under the SOLAS (Safety Of Life At Sea) Convention are determined by the communication functions of Global Maritime Distress and Safety System (GMDSS). This system was fully implemented on the $1^{\text {st }}$ February 1999, and since then maritime communications methods have not been significantly changed. As a result, numerous researches and studies were conducted, intended to improve existing communication systems. Furthermore, the exchange of data in maritime communications is of great importance for the purpose of safety of navigation and commercial services. For this reason, the advantages and disadvantages of existing maritime communication systems for data exchange are systematically analyzed in this paper, in order to determine the guidelines for their improvement or replacement by new communication systems. The focus is on the used modulation techniques, as well as the maximum achieved data rates. According to these characteristics the possibility of applying certain communication systems in communications infrastructure of the strategy called "e-Navigation" is determined. In addition, an overview of international recommendations and guidelines for the modernization of maritime communications in the VHF frequency band is elaborated in this paper.
\end{abstract}

\section{ARTICLE INFO}

Review article

Received 1 April 2016

Accepted 30 May 2016

Key words:

GMDSS

Maritime data exchange

e-Navigation

VHF Data Exchange System

\section{Introduction}

In maritime transport, radiocommunication systems are used for communication between ships, as well as for communication between ships and land facilities, and also for communication between users of various communication services. Considering the maritime affair, these radiocommunication systems are divided into terrestrial and satellite communication systems.

Terrestrial maritime radiocommunication systems use electromagnetic waves in medium frequency (MF), high frequency (HF) and very high frequency (VHF) bands according to International Telecommunication Union (ITU) division. The electromagnetic waves of those frequency ranges propagate through the communication channels in different ways. Particularly, electromagnetic waves can be described with three propagation components: surface wave, space wave and sky wave. The surface wave is the most pronounced component in the MF frequency band; the space wave (precisely the line of sight space wave) is the most pronounced component in the VHF frequency band; while the sky wave is the most pronounced component in the HF frequency band.
According to Global Maritime Distress and Safety System (GMDSS), the following terrestrial radio communication systems are used for ship-to-ship and ship-to-shore communication:

- analog radiotelephone communications systems on the MF, HF and VHF frequency bands;

- digital radiotelex communication systems on the MF and HF frequency bands; and

- digital radiocommunication systems for selective calling (DSC's) on the MF, HF and VHF frequency bands.

Another terrestrial digital system that uses communication channels from the maritime VHF frequency band is the automatic identification system (AIS). However, this system is primarily used in navigation for identifying and locating ships.

As opposed to terrestrial systems, satellite maritime radio communication systems use electromagnetic waves in ultra high frequency (UHF) and super high frequency (SHF) bands according to ITU division. The direct propagation (from transmitter to receiver) of electromagnetic waves is generally the most common propagation mode at UHF and SHF frequency bands. 
According to GMDSS, satellite radio communication systems that are used in the maritime communications are the following: the private commercial INMARSAT (International Maritime/Mobile Satellite) system and the international COSAPAS-SARSAT (Cosmicheskaya Sistyema Poiska Avariynich Sudov - Search and Rescue SatelliteAided Tracking) system which is used only for search and rescue needs.

The satellite INMARSAT system supports multiple communication services such as digital voice communications, exchange of large amounts of data (due to highspeed transmission) and connection through the Internet Protocol (IP).

\section{Maritime communication systems for data exchange}

A detailed description of all aforementioned maritime terrestrial and satellite radio communication and navigation systems is presented in this section.

\subsection{Maritime terrestrial communication system for digital selective calling}

Digital selective calling (DSC) is an integral part of the GMDSS system. It is used for sending distress alerts from ships as well as for sending acknowledgments of these alerts from a coast station. In certain cases, a ship station can also send acknowledgment of the distress alert [1]. DSC is also used for relaying the distress alerts by the coast and ship stations. Furthermore, it provides calling i.e. notifications of additional communications of urgency, safety and routine priorities [2].

\subsubsection{Types of DSC calls}

The selectivity of the system implies an easy selection of one or more ships or coast stations that will receive the transmitted call. DSC supports several call types as follows:

1. Distress call;

2. Distress relay call;

3. All stations call;

4. Individual call;

5. Group call; and

6. Geographical area call.

Each call is predefined and it generally consists of several elements:

- dot pattern (for detecting upcoming calls);

- phasing sequence (for synchronization of transmitted symbols between transmitter and receiver at the bitlevel);

- format specifier;

- address;

- category;
- self-identification;

- messages (for inserting additional information);

- end of sequence (in which the need of transmitting the acknowledgment of the received call is indicated); and

- error check character.

According to the previous description, the DSC system is not a conventional communication system but it is used, by transmitting predefined messages, for the notification of additional communications of all GMDSS priorities (distress, urgency, safety and routine communications) that can occur on the terrestrial radiotelephone and/or radiotelex devices.

\subsubsection{Modulation types and data rates of the DSC system}

As stated before, the DSC system is a terrestrial system, therefore it uses all three maritime terrestrial frequency bands i.e. MF, HF and VHF. Due to different frequency bands, there are different modulation types of carrier waves causing different data rates. Consequently, the direct Frequency Shift Keying (FSK) modulation of carrier wave is used on maritime MF/HF radiochannels of 500 $\mathrm{Hz}$ bandwidth. In the case of an indirect modulation an additional audio frequency subcarrier is used, resulting in Audio Frequency Shift Keying (AFSK) modulation. The shift between corresponding frequencies is $170 \mathrm{~Hz}$ and the achieved data rate is $100 \mathrm{bit} / \mathrm{s}$. Considering the VHF frequency band, there is only one communication channel of $25 \mathrm{kHz}$ bandwidth which is used for DSC communication system. On this channel, a digital frequency modulation of carrier wave with pre-emphasis of $6 \mathrm{~dB}$ per octave is used resulting in the Phase Shift Keying (PSK) modulation. The shift between baseband frequencies is $800 \mathrm{~Hz}$ and the achieved data rate is $1200 \mathrm{bit} / \mathrm{s}$ [3].

\subsubsection{Encoding of the DSC system}

The DSC system is a digital synchronous system that uses ten-bit error detecting code. The first seven bits of the ten-bit code are information bits (128 different characters) while the remaining three bits are error detecting bits (providing information of zero bits within each character). For the purpose of error correction, every character is transmitted twice with time delay which corresponds to the transmission time of four following characters that need to be transmitted. Considering the ten-bit code and different transmission rates on the VHF and MF/HF frequency bands, a time delay for transmitting the same character on VHF frequency band is:

time delay $_{V H F}=4$ characters $\cdot \frac{10 \text { bits }}{1200 \mathrm{bit} / \mathrm{s}}=33.33 \mathrm{~ms}$,

while on MF/HF frequency band, a time delay is:

${\text { time } \text { delay }_{M F / H F}}=4$ characters $\cdot \frac{10 \mathrm{bits}}{100 \mathrm{bit} / \mathrm{s}}=400 \mathrm{~ms}$. 
Also, at the end of each DSC call, there is a character that is used to detect errors in the entire call which were not detected with the previously described methods [3].

\subsection{The maritime terrestrial radiotelex system and international NAVTEX system}

The maritime radiotelex system is a digital system which belongs to the group of systems known as NarrowBand Direct Printing (NBDP). It provides two operating modes: Automatic Repetition reQuest (ARQ) and Forward Error Correction (FEC).

Using ARQ mode of the radiotelex system, it is possible to establish communication as follows:

- between a ship and a coast station;

- between a ship and some other device, through a coast station;

- between a ship and a user of the terrestrial international telex network; and

- between two ships.

According to the communication priorities of the GMDSS system, routine communications are usually performed using ARQ mode of the radiotelex system.

Considering the FEC mode of the radiotelex system, it is not possible to establish a classic "two-way" communication between two stations. The FEC mode is used when a ship or a coast station transmits the same data (message) to several ships, i.e. it is used for broadcasting. Furthermore, this mode is recommended for performing the communications of distress, urgency and safety which are announced by DSC devices [4].

\subsubsection{Technical characteristics of maritime radiotelex system}

The radiotelex system is a terrestrial communication system which is used on the maritime MF and HF frequency bands. The term NBDP refers to communication channel bandwidth of $500 \mathrm{~Hz}$ and corresponds to the channel bandwidth provided for the MF/HF DSC system. In other words, it can be seen that the MF/HF radiotelex system has the equal modulation technique as the MF/HF DSC system.

Therefore, the MF/HF radiotelex system also uses the direct FSK modulation of carrier wave on maritime MF/HF radiochannels of $500 \mathrm{~Hz}$ bandwidth. As stated before, in the case of an indirect modulation an additional audio frequency subcarrier is used, resulting in Audio Frequency Shift Keying (AFSK) modulation. Furthermore, the shift between corresponding frequencies is $170 \mathrm{~Hz}$ and the achieved data rate is $100 \mathrm{bit} / \mathrm{s}$.

Moreover, the radiotelex system is also a synchronous system that uses the International Telegraph Alphabet No. 2 7-bit encoding. The first five bits of the seven-bit code are information bits (32 different characters) while the remaining two bits are error detecting bits [5].
During the communication process, radiotelex system uses several types of transmitted signals:

- information signals;

- signals for establishing and maintaining a connection (control signals, idle signals, signal repetition);

- identification signals; and

- check-sum signals.

\subsubsection{Description of the ARQ working mode}

The synchronous communication between two stations is established when choosing the ARQ working mode. The station that starts the communication is named "MASTER" while the station that receives the call is named "SLAVE". Moreover, irrespective to the "MASTER" and "SLAVE" classification, information sending station (ISS) and information receiving station (IRS) are defined in each cycle of data exchange.

During every cycle of data exchange between ISS and IRS, the information block (that contains three characters) is sent by ISS and subsequently the response (that contains control signals) is sent by IRS. Control signals are used to notify the ISS about successful or unsuccessful data receipt. If any individual character within information block is unsuccessfully received, the ISS transmits the same information block until it receives a control signals that indicate successful data receipt.

The time interval for each cycle of data exchange between ISS and IRS is $450 \mathrm{~ms}$. Within this time interval, time interval of $210 \mathrm{~ms}$ is reserved for transmitting an information block while the time interval of $70 \mathrm{~ms}$ is reserved for transmitting control signals. The time interval of one cycle is longer than the time interval intended for sending information and control signals, because of a time delay of radiowaves which are propagated over long distances on the MF and HF frequency bands. Moreover, the IRS has additional time delay i.e. time required for switching the station from the receiving mode to the transmitting mode [6].

\subsubsection{Description of the FEC working mode}

In FEC working mode, a continuous data stream is transmitted from one station to all stations within the range (Collective FEC) or to only one particular station (Selective FEC).

Every character is transmitted twice with time delay which corresponds to the transmission time of four following characters that need to be transmitted. The sending process is similar to DSC system. As each character contains 7 bits and the transmission rate of the radiotelex system is $100 \mathrm{bit} / \mathrm{s}$, a time delay for transmitting the same character is:

time delay $=4$ characters $\cdot \frac{7 \text { bits }}{100 \mathrm{bit} / \mathrm{s}}=280 \mathrm{~ms}$.

In order to prepare receiving stations on the FEC working mode, the sending station sends pairs of so-called 
phasing signals (control signals for phase synchronization). In this way, the receivers are actually synchronized with upcoming signals. It is necessary to transmit at least 16 pairs of phasing signals due to higher probability of detection and synchronization.

After the transmission of phasing signals, the station transmits information signals. The receiving stations check the validation of every received character. If one of two equal characters is successfully received (which is checked based on two error detecting bits) then this character is printed i.e. displayed on the terminal of receiver. Otherwise, the information about the erroneously received character is displayed [6].

The disadvantage of FEC working mode is the absence of the feedback about the successful or unsuccessful receipt.

\subsubsection{International NAVTEX system}

The international Navigational Telex (NAVTEX) is a system for coordinated transmission of maritime safety information (MSI) from the coast stations and automatic reception by the ship stations. In general, MSI is a collection of navigational and meteorological warnings, meteorological forecasts and other important information related to the safety of navigation. The message providers of MSI are the following [2]:

- national hydrographic institutes - provide the information related to navigational warnings and corrections of electronic charts;

- national meteorological institutes - provide the information related to meteorological warnings and forecasts;

- search and rescue centers - provide the distress alerts and urgent and safety related information;

- international Ice patrol - provides the information related to icebergs at the North Atlantic.

The transmission of MSI is coordinately transmitted on the areas that are called NAVAREAs (Navigational Area) and METAREAs (Meteorological Area). There are 21 such navigational/meteorological areas that are managed by national NAVAREA/METAREA coordinators.

The international NAVTEX system also belongs to the already mentioned group of NBDP devices and systems. This system is actually a radiotelex system that uses FEC working mode for transmitting different MSI, i.e. NAVTEX messages from the coast NAVTEX stations to the ship NAVTEX receivers. The NAVTEX messages written in English are transmitted on the international frequency of $518 \mathrm{kHz}$ which belongs to the MF frequency band. Also, there are two additional frequencies for transmitting NAVTEX messages in national languages: frequency of $490 \mathrm{kHz}$ (MF frequency band) and $4209.5 \mathrm{kHz}$ (HF frequency band).

There is a total 25 NAVTEX stations for transmitting NAVTEX messages within each NAVAREA/METAREA area. These stations are marked with letters of English alphabet. There are 24 active NAVTEX stations (letters from A to
$\mathrm{X}$ ) and one backup NAVTEX station (letter Z). All NAVTEX stations transmit messages in the period of 10 minutes every 4 hours according to previously defined timetable, in order to avoid mutual interference at the same frequency, i.e. communication channel. Moreover, all stations transmit the messages with limited transmission power to avoid mutual interference between stations marked with the same letter in adjacent NAVAREA/METAREA areas [1].

Furthermore, NAVTEX messages are also marked with letters of English alphabet according to the Table 1.

Table 1 Indicators and subjects of NAVTEX messages

\begin{tabular}{|c|l|}
\hline Indicator & \multicolumn{1}{|c|}{ Subject } \\
\hline A & Navigational warnings \\
\hline B & Meteorological warnings \\
\hline C & Ice reports \\
\hline D & $\begin{array}{l}\text { Search And Rescue (SAR) information, piracy } \\
\text { and armed robbery warnings, tsunamis and } \\
\text { other natural phenomena }\end{array}$ \\
\hline E & Meteorological forecasts \\
\hline F & $\begin{array}{l}\text { Pilot service and VTMIS (Vessel Traffic } \\
\text { Management and Information System) } \\
\text { messages }\end{array}$ \\
\hline G & AIS messages \\
\hline H & LORAN messages \\
\hline I & Currently not used \\
\hline J & GNSS messages \\
\hline K & $\begin{array}{l}\text { Other electronic navigational aid system } \\
\text { messages }\end{array}$ \\
\hline L & Other navigational warnings (overflow from A) \\
\hline Z & Currently not used \\
\hline M, N, O, P, Q R, S, T, U & Special Services - for NAVTEX coordinators \\
\hline V, W, X, Y & No messages on hand \\
\hline
\end{tabular}

Source: [7]

Unlike the standard radiotelex messages that are transmitted with FEC working mode, each NAVTEX message starts with a group of 4 symbols as follows:

- the indication of NAVTEX station that transmits the message;

- the indication of NAVTEX message that is transmitted;

- a serial number of NAVTEX message that is transmitted from listed NAVTEX station (indication from 01 to 99).

Standard NAVTEX ship devices consist of receiver, processor, display and/or printer for viewing and/or printing of the received NAVTEX messages.

\subsection{Automatic identification system}

The automatic identification system (AIS) is the autonomous communication system, which uses two channels of the maritime VHF frequency band for the transmission of relevant navigational data and/or other information related to the safety of navigation. The AIS system improves 
the safety of navigation and protection of the sea and maritime environment enabling efficient navigation and operation of the VTMIS. Therefore, the main purpose of introducing the AIS system is reflected in [8]:

- increasing the situational awareness at sea;

- improving traffic management in congested navigational areas;

- automatic reporting in areas of mandatory and voluntary reporting; and

- exchange of safety related information.

\subsubsection{Data types of automatic identification system}

According to the above, the data which is automatically transmitted between the ship AIS station and/or between ship and land AIS stations can be divided into three categories: static information, dynamic information and voyage related information.

Static data, as their name implies, do not change during the voyage but are entered during the installation of AIS station, and include: Maritime Mobile Service Identity (MMSI) of the ship, call sign and name of the ship, International Maritime Organization (IMO) number of the ship, length and width of the ship, type of the ship, and the position of the antenna of the positioning system onboard ship.

On the other hand, the dynamic data obtained from various ship's sensors are changed during the voyage, and include: ship's position, Universal Time Coordinated (UTC), ship's course and speed, ship's heading, navigational status, and ship's drift speed.

Voyage related data are entered manually during the voyage, and include: ship's draft, type of (hazardous) cargo, destination and estimated time of arrival, and voyage plan.

Moreover, there are so called short safety related messages which, as required, are manually transmitted between ships or between ships and land stations.

In general, the static data and voyage related data are transmitted every six minutes or on demand. Dynamic data are transmitted depending on the change of speed and course of the ship, and the reporting time intervals may vary from two seconds to three minutes (Table 2) [9].
Due to its technology and efficiency, AIS became mandatory for vessels which are not under the SOLAS Convention. Furthermore, AIS technology or AIS channels, apart from transmitting the above static, dynamic and voyage related data, are also used for transmitting messages and information such as Aids to Navigation (AtoN), Application Specific Messages (ASM), AIS Search and Rescue Transmitter (SARTAIS), Man Over Board Unit (MOB), and AIS Emergency Position-Indicating Radio Beacon (EPIRB-AIS).

\subsubsection{Technical characteristics and operation of the AIS system}

There are several classes of AIS ship stations, of which, according to the IMO, the ships can use Class A or Class B. Hereinafter, technical features and operation of AIS Class A stations are described and analyzed. Standard ship AIS station consists of $[10,11]$ :

- three standalone VHF receivers: two of which are intended to monitor AIS 1 (161.975 MHz) and AIS 2 $(162.025 \mathrm{MHz})$ channels, while the third is intended for monitoring the VHF DSC channel 70 (156.525 $\mathrm{MHz}$;

- one transmitter, which continually alternates the transmission on the AIS 1 and AIS 2 channels;

- keyboard, display and control unit, which contains a processor and interfaces needed to exchange data from the ship's sensors to external devices, such as ECDIS (Electronic Chart Display and Information System), ARPA (Automatic Radar Plotting Aid), VDR (Voyage Data Recorder) etc.; and

- one or more GPS / DGPS receivers, which provide information about the ship's position, as well as the precise time required to synchronize multiple AIS stations for data transmission on two maritime VHF communication channels.

AIS system uses a frequency modulated Gaussianfiltered Minimum Shift Keying (GMSK) modulation technique of the carrier wave for data transmission on AIS 1 and AIS 2 channels of $25 \mathrm{kHz}$ or $12.5 \mathrm{kHz}$ bandwidth. The principle of the abovementioned modulation technique is as follows: AIS station data, which need to be transmit-

Table 2 Dynamic data reporting time intervals

\begin{tabular}{|l|c|}
\hline \multicolumn{1}{|c|}{ Ship's dynamic conditions } & Reporting time interval \\
\hline Ship at anchor or moored and not moving faster than 3 knots & $3 \mathrm{~min}$ \\
\hline Ship at anchor or moored and moving faster than 3 knots & $10 \mathrm{~s}$ \\
\hline Ship moving 0-14 knots & $10 \mathrm{~s}$ \\
\hline Ship moving 0-14 knots and changing course & $31 / 3 \mathrm{~s}$ \\
\hline Ship moving 14-23 knots & $6 \mathrm{~s}$ \\
\hline Ship moving 14-23 knots and changing course & $2 \mathrm{~s}$ \\
\hline Ship moving > 23 knots & $2 \mathrm{~s}$ \\
\hline Ship moving > 23 knots and changing course & $2 \mathrm{~s}$ \\
\hline
\end{tabular}

Source: [9] 


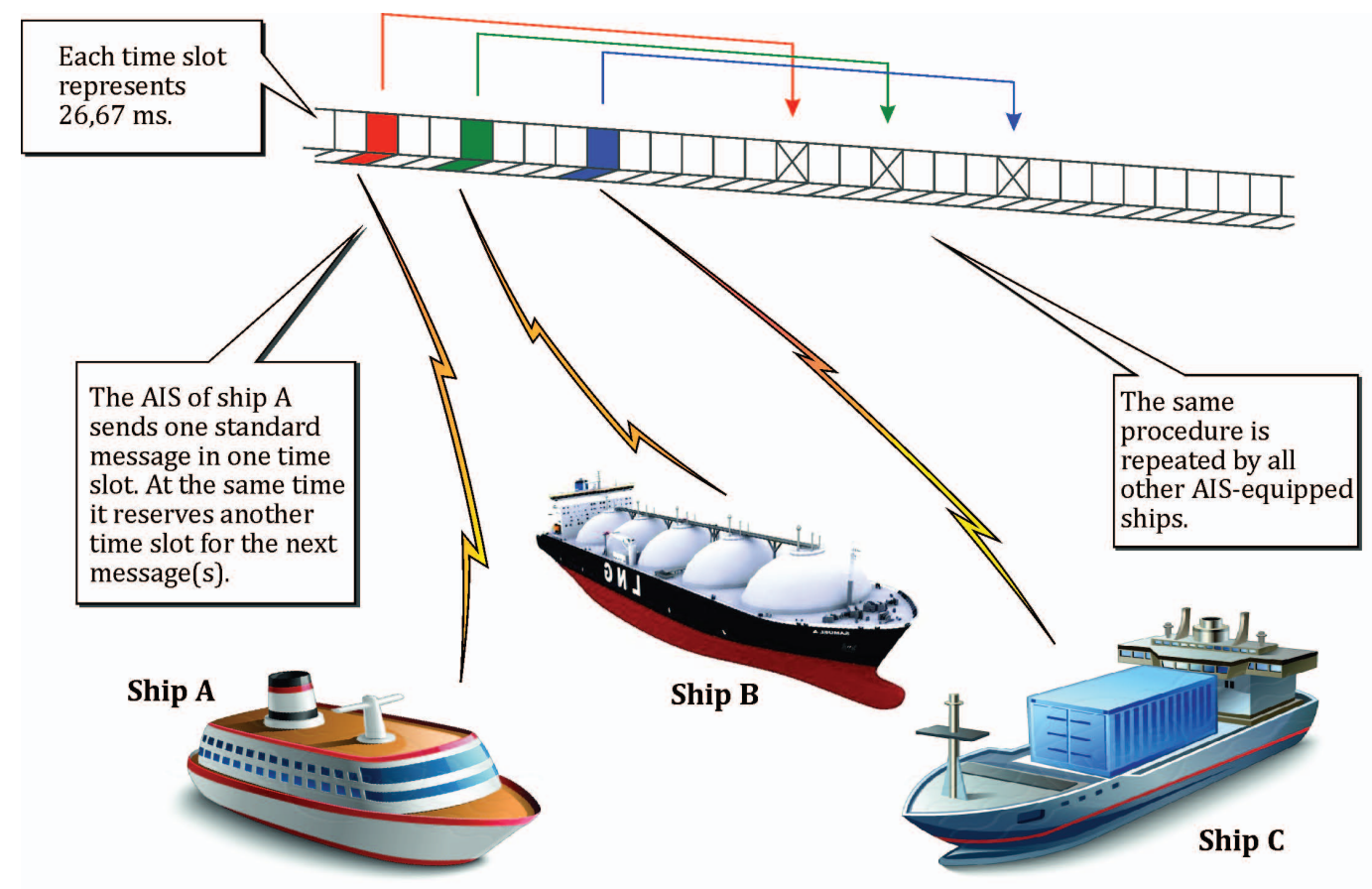

Figure 1 Self-organizing time division multiple access

Source: According to [8]

ted, are first coded by GMSK modulation, and as such are used for frequency modulation of carrier waves of AIS 1 or AIS 2 channels. Using this modulation technique, with a modulation index of 0.5 , it is possible to achieve a data rate of $9.6 \mathrm{kbit} / \mathrm{s}$. For the purpose of avoiding unwanted signal interferences and loss of data by other AIS stations, AIS system interchangeably uses two VHF communication channels.

Furthermore, AIS system uses the so-called self-organizing time division multiple access (SOTDMA) protocol, which enables multiple AIS stations access to the same channels. Namely, stations of AIS system are synchronized based on timing data from the GPS/DGPS receivers, and every one minute time frame, provided for AIS data transmission on a single communication channel, is divided into 2,250 time slots. This results in a $26.67 \mathrm{~ms}$ for each time slot. In addition, as the data rate is $9.6 \mathrm{kbit} / \mathrm{s}$, then in each time slot a total of 256 bits of information can be transmitted, which relates to a standard automatic AIS message, i.e. AIS report. Some AIS messages can take up to five consecutive time slots. Each AIS station randomly selects the use of a certain time slot within a certain time frame, and depending on the time interval of data updating, pre-occupies the next time slot (Figure 1).

\subsection{Satellite radio communication system INMARSAT}

In comparison with the maritime terrestrial communication systems, INMARSAT is global satellite com- munication system. INMARSAT system or organization was developed in 1976 at the international conference of the IMO, and it was accepted as an intergovernmental organization in 1979. At that time, the main purpose of INMARSAT system was improving maritime communications, especially from the aspect of distress communications and communications related to the safety of life at sea. However, in 1999 the system became privatized, and expanded its purpose from providing services for the purposes of maritime communications to the provision of services on a global level for different types of users [2].

\subsubsection{Parts of INMARSAT satellite system}

INMARSAT system consists of three main segments:

1. space or satellite infrastructure;

2. Earth or land control and communication infrastructure; and

3. users' infrastructure.

Space or satellite infrastructure consists of four active communication satellites, which are located in geostationary orbit at $35,786 \mathrm{~km}$ above the equator. These four satellites, with the elevation of $5^{\circ}$, are covering the Earth's surface from $70^{\circ}$ South to $70^{\circ}$ North latitude, which actually represents the sea area A3 according to the GMDSS. As these satellites cover the navigational areas of the world's oceans, they are called respectively:

1. satellite AOR-E (Atlantic Ocean Region - East), covering an area of the Eastern Atlantic Ocean; 
2. satellite AOR-W (Atlantic Ocean Region - West), covering an area of the Western Atlantic Ocean;

3. satellite POR (Pacific Ocean Region), covering an area of the Pacific Ocean; and

4. satellite IOR (Indian Ocean Region), covering an area of the Indian Ocean.

Earth or land infrastructure consists of the control centres and stations, as well as of the communication stations. Control headquarters of INMARSAT system are called Network Control Centre (NCC) and are located in the UK, London, where the headquarters of the private organization Inmarsat are also situated. NCC continuously monitors entire INMARSAT system, and coordinates a wide range of activities within the system. In different literature, this control centre is also known as NOC (Network Operations Centre) and OCC (Operating Control Centre) $[1,2]$.

Furthermore, the INMARSAT system is so-called indirect system, i.e. all communications are carried out through Coast Earth Stations (CES) or Land Earth Stations (LES). These Earth stations are in the possession of multinational telecommunication operators, i.e. in the possession of a communications providers. Land stations that monitor and control communications under one of the four INMARSAT satellites are called Network Coordination Stations (NCS). The role of monitoring and managing communications, i.e. the role of NCS can be performed by some CES or LES.

The last segment of the INMARSAT system is comprised of users, i.e. their mobile communication stations. Although hereinbefore is stated that the INMARSAT system is used for all types of transportation, only maritime mobile stations are analyzed in this paper.

\subsubsection{Ship Earth Stations of INMARSAT system}

Mobile stations of INMARSAT system used for maritime communications are called Ship Earth Stations (SES). There are different types of INMARSAT Ship Earth Stations, but according to the requirements and priorities of GMDSS communications only INMARSAT B, INMARSAT $\mathrm{C}$ and INMARSAT Fleet F77 can be used onboard ships. Moreover, for the reception of maritime safety information, as well as of short commercial notifications the Enhanced Group Call (EGC) receiver is used. Furthermore, INMARSAT stations called Fleet Broadband enabling broadband Internet access can also be used onboard ships.

Ship Earth Stations of the INMARSAT system support almost all types of communications and communication services that can be undertaken in land terrestrial or satellite networks. These stations provide ships with reliable communications using high quality telephone communications, data communications, telex communications, etc. [1].

The frequencies used for communications within the INMARSAT system are in UHF and SHF frequency bands, according to the ITU division, i.e. in L and C fre- quency bands according to the Institute of Electrical and Electronics Engineers (IEEE) division. For communications between the Coast Earth Stations and satellites the channels in $4 \mathrm{GHz}$ and $6 \mathrm{GHz}$ frequency bands are used, while for communications between Ship Earth Stations and satellites the channels in $1.5 \mathrm{GHz}$ and $1.6 \mathrm{GHz}$ frequency bands are used.

The INMARSAT C Ship Earth Station was introduced in 1991 as a supplement to the INMARSAT A station. Namely, the INMARSAT A Ship Earth Station was introduced in 1982, but was withdrawn from service at 31 December 2007, due to obsolete analog mode, technical characteristics and large physical dimensions. Unlike the INMARSAT A station, the INMARSAT C station provides cost effective communications using very small omnidirectional antenna. However, the INMARSAT C Ship Earth Station does not provide telephone communications, but works on the principle called "store-and-forward messaging". This principle is similar to the operating mode of electronic mail, where messages or data, after a certain time delay, are transmitted to satellites and coast Earth stations with data rate of only $600 \mathrm{bit} / \mathrm{s}$. The INMARSAT C station uses digital binary phase shift keying (BPSK) modulation [12].

The INMARSAT B Ship Earth Station was introduced in 1994, as a digital replacement to the abovementioned outdated analog INMARSAT A station. This station provides a highly reliable voice communications, telex communications, and transmission of fax messages and data, including E-mailing, achieving data rates from $9.6 \mathrm{kbit} / \mathrm{s}$ to 64 kbit/s. The INMARSAT B Ship Earth Station uses different types of digital phase shift keying (PSK) modulation. The disadvantage of this type of INMARSAT station is its directed antenna of rather large dimensions, and its withdrawal from service is announced at the end of 2016 [13].

The INMARSAT Fleet F77 Ship Earth Station, introduced in 2001, is fully compatible with the requirements and priorities of the GMDSS system, supporting voice communications with new spectral efficient coding method and transmission of data and fax messages, allowing data rates up to $128 \mathrm{kbit} / \mathrm{s}$. The INMARSAT Fleet F77 Ship Earth Station uses different types of digital PSK modulation, and quadrature amplitude modulation (QAM) [14].

\section{Overview of international recommendations and guidelines}

Safety at sea, which includes the protection of the crew, passengers, cargo and maritime environment, depends primarily on the availability of radio communication systems, or devices.

International organizations and regional or national agencies have set a series of objectives and requirements relating to the interoperability, reliability, functionality and operation safety. Due to the growth of radio communication needs of maritime users at sea and infrastructure providing safety and support on land, future advanced solutions in the maritime communications will require in- 
Table 3 VHF channels and frequencies used for VDES system

\begin{tabular}{|c|c|c|}
\hline Channel & \multicolumn{2}{|c|}{ Frequencies for ship and coast stations (MHz) } \\
\hline AIS 1 & 161.975 & 161.975 \\
\hline AIS 2 & 162.025 & 162.025 \\
\hline 2027 (ASM 1) & $161.950(2027)$ & $161.950(2027)$ \\
\hline 2028 (ASM 2) & $162.000(2028)$ & $162.000(2028)$ \\
\hline $24(\operatorname{VDE} 1)$ & $157.200(1024)$ & $161.800(2024)$ \\
\hline 84 (VDE 2) & $157.225(1084)$ & $161.825(2084)$ \\
\hline 25/85/26/86 (VDE 4, SAT2) & $\begin{array}{l}100 \mathrm{kHz} \text { channel bandwidth } \\
(25 / 85 / 26 / 86, \text { lower frequencies, merged) }\end{array}$ & $\begin{array}{l}100 \mathrm{kHz} \text { channel bandwidth } \\
(25 / 85 / 26 / 86, \text { upper frequencies, merged) }\end{array}$ \\
\hline 25 & $157.250(1025)$ & $161.850(2025)$ \\
\hline 85 & $157.275(1085)$ & $161.875(2085)$ \\
\hline 26 & $157.300(1026)$ & $161.900(2026)$ \\
\hline 86 & $157.325(1086)$ & 161.925 (2086) \\
\hline
\end{tabular}

Source: [15]

creased global coverage, higher data rates, as well as video and/or multimedia features [15].

At the World Radiocommunication Conference, held in 2012 in Geneva, two Resolutions (359 and 360) relating to the improvement of maritime communications were issued. According to these Resolutions the ITU is required to conduct research and studies related to new radio communication systems, which will modernize the GMDSS system and unload communication channels of the AIS system. Furthermore, the need for consideration of the new regulations, including the reallocation of maritime frequency spectrum is also underlined, in order to enable the modernization of the GMDSS system, and therefore enabling the implementation of the strategy called "e-Navigation".

As defined by the IMO, "e-Navigation is the harmonized collection, integration, exchange, presentation and analysis of maritime information onboard and ashore by electronic means to enhance berth to berth navigation and related services, for safety and security at sea and protection of the marine environment" [15].

There are three key elements that must be satisfied, i.e. set before the implementation of "e-Navigation", which are [15]:

1. coverage of all navigational areas of the world by Electronic Navigation Charts (ENCs);

2. a robust electronic positioning, navigation and timing system (with redundancy); and

3. an agreed and accepted communication infrastructure to connect ships and land facilities.
Hereafter, the recommendations, suggestions and guidelines regarding maritime VHF frequency band with the aim of modernizing the GMDSS, unloading the AIS system and laying the foundations of communication infrastructure of "e-Navigation", will be analyzed in details.

\subsection{Maritime VHF Data Exchange System}

According to ITU's Radio Regulations, in the maritime VHF frequency band there is a total of 59 numbered channels, each of $25 \mathrm{kHz}$ bandwidth. Among these channels, 56 of them are allocated for various analog radiotelephone communications, two channels (channels AIS 1 and AIS 2) are allocated for AIS system, and only one channel (channel 70) is allocated for digital selective calling, i.e. for VHF DSC system. On the previously mentioned World Radiocommunicaton Conference, the reallocation of several channels in the maritime VHF frequency band has been determined. Thus, the adjacent channels 24, 84, 25, 85, 26 and 86 are intended for testing and application of new digital communication technologies, and it is anticipated that channels $80,21,81,22,82,23$ and 83 will also be assigned for the same purpose. Moreover, the testing of future applications of AIS system on channels 27, 28, 87 and 88 is allowed from the 1 January 2013 [17].

The International Association of Marine Aids to Navigation and Lighthouse Authorities (IALA) has developed a technology concept called VHF Data Exchange System (VDES) with the purpose of solving problems regarding AIS channels congestion and its efficiency degradation [16]. At 
the same time, the VDES system allows a wide exchange of information envisaged by the strategy "e-Navigation", which also potentially supports the modernization of the GMDSS system [15]. The VDES system will prospectively have a significant positive impact on the provision of maritime information services, including: maritime safety information and messages, general data communications, robust data exchange at high data rates, locating, vessel traffic management, satellite communications, etc. From the functional point of view, the VDES system uses a two-way data exchange on channels from maritime VHF frequency band in the following directions of communication (Table 3):

- between ships;

- between ships and shore; and

- between ships and satellites.

The data, which can be transmitted and/or exchanged using VDES system, are following:

- AIS: standard AIS report, i.e. message which includes static, dynamic and voyage related data;

- ASM: Application Specific Messages, e.g. for transmitting navigational, meteorological and hydrographical information;

- VDE: general exchange of information on the maritime VHF frequency band; and

- SAT: data transmission between ships and satellites.

\subsection{Recommendation of the International Telecommunication Union ITU-R M.1842-1}

The Recommendation ITU-R M.1842-1 entitled "Characteristics of VHF radio systems and equipment for the exchange of data and electronic mail in the maritime mobile service RR Appendix 18 channels" describes four examples of systems and equipment which could be used in the maritime VHF frequency band for the exchange of data and electronic mail. This recommendation should serve as a guideline for the development and implementation of future digital technologies in the maritime VHF frequency band, in order to modernize the GMDSS and unload the AIS system, while laying the foundations of the communication infrastructure of "e-Navigation".

The first proposed system uses a single channel of 25 $\mathrm{kHz}$ bandwidth from the maritime VHF frequency band. Furthermore, this system can use two types of modulation techniques: $\pi / 4$ DQPSK or $\pi / 8$ D8-PSK. Using the first modulation technique the proposed system can achieve a data rate of $28.8 \mathrm{kbit} / \mathrm{s}$, while using the second modulation technique can achieve $43.2 \mathrm{kbit} / \mathrm{s}$.

The second proposed system describes the existing regional narrowband VHF system for the exchange of data and electronic mail, which is used along the coast of Norway. This system uses nine channels of $25 \mathrm{kHz}$ bandwidth from the maritime VHF frequency band. The modulation technique used in this system is a quaternary GMSK, and the system achieves data rate of $21.1 \mathrm{kbit} / \mathrm{s}$ within one of abovementioned channels.
The third proposed system is a system with multiple carrier waves or subcarriers, and uses two adjacent channels of $25 \mathrm{kHz}$ bandwidth from the maritime VHF frequency band, i.e. one channel of $50 \mathrm{kHz}$ bandwidth. The ITU recommends that this system uses 16 subcarrier waves, modulated by 16-QAM modulation technique, within the channel of $50 \mathrm{kHz}$ bandwidth. This is defined according to the standard of the European Telecommunications Standards Institute (ETSI), entitled EN 300 392-2 v.3.2.1, and thereby, with the above features, it is possible to achieve a data rate of $153.6 \mathrm{kbit} / \mathrm{s}$.

The fourth, and also the last proposed system, also represents a system with multiple carrier waves or subcarriers, and uses four adjacent channels of $25 \mathrm{kHz}$ bandwidth from the maritime VHF frequency band, i.e. one channel of $100 \mathrm{kHz}$ bandwidth. The ITU recommends that this system uses 32 subcarrier waves, modulated by the same modulation technique and by the same standard as the previous system, which results in a data rate of $307.2 \mathrm{kbit} / \mathrm{s}$.

\section{Conclusion}

The exchange or transmission of data between ships and land facilities is of great importance for the purpose of safety of navigation, as well as for the commercial services. For this reason, radiocommunication systems that are currently used onboard ships for various data exchange were analyzed in this paper. However, each of these systems has its drawbacks in terms of their acceptance in the communication infrastructure of "e-Navigation". Namely, the DSC system allows a maximum data rate of $1200 \mathrm{bit} / \mathrm{s}$ (VHF DSC), and it is possible only to transfer messages, or information predefined in standard six types of DSC calls.

Maritime radiotelex system is considered as outdated mode of communication, which is barely used for routine or general communications between ships and between ships and shore stations. Furthermore, as the data rate achieved by this system is only $100 \mathrm{bit} / \mathrm{s}$ with the addition of using a 5-bit code, it is not possible to transfer large amounts of data in real time, which makes it unusable in communication infrastructure of "e-Navigation". The abovementioned facts also refer to the international NAVTEX system, which is actually a maritime radiotelex system in the FEC operating mode.

The AIS system represents a new communication technology on maritime VHF frequency band. This system effectively uses two channels from specified frequency band to send data at a rate of $9600 \mathrm{bit} / \mathrm{s}$, therefore it will be a part of the communication infrastructure of "e-Navigation" in future. However, due to the increased use of AIS in some navigational regions of the world, the congestion of AIS channels and degradation of AIS system efficiency have occurred, which resulted in assigning the abovementioned new channels, as well as seeking for new data exchange solutions on the maritime VHF frequency band.

The satellite INMARSAT system will also form a part of the communication infrastructure of "e-Navigation", due 
to its characteristics and provision of a wide range of features and services. However, due to the high cost of services, as well as lack of coverage of INMARSAT satellites in the areas of Earth's poles, its replacement and/or upgrade by reliable terrestrial systems for data exchange will be required.

The replacement and/or upgrade of these maritime radiocommunication systems, as well as the introduction of new technologies will lay the foundations of the communication infrastructure of the "e-Navigation" and also modernize the current GMDSS system.

\section{References}

[1] ITU, "Manual for use by the Maritime Mobile and Maritime Mobile-Satellite Services", Geneva, 2011.

[2] IMO, "Manual on the Global Maritime Distress and Safety System", London, 2007.

[3] Recommendation ITU-R M.493-13, "Digital selective-calling in the maritime mobile service", 2009.

[4] Recommendation ITU-R M.492-6, "Operational procedures for the use of direct-printing telegraph equipment in the maritime mobile service", 1995.

[5] Recommendation ITU-R M.625-4, "Direct-printing telegraph equipment employing automatic identification in the maritime mobile service", 2012.
[6] Mrak, Z., "Komunikacijski uređaji i postupci u GMDSS sustavu", Rijeka, Visoka pomorska škola, 2001.

[7] International Maritime Organization, "MSC Circular 1403 Revised NAVTEX Manual”, London, 2011.

[8] IALA Guideline No. 1082, “On an Overview of AIS”, $1^{\text {st }}$ ed. France, 2011.

[9] Recommendation ITU-R M.1371-5, “Technical characteristics for an automatic identification system using time division multiple access in the VHF maritime mobile frequency band", 2014.

[10] Kitarović, J. et al., "ECDIS training course - trainee manual", Rijeka: University of Rijeka, Faculty of Maritime Studies, 2002.

[11] Leica Geosystems Inc., "The Complete Guide to Automatic Identification Systems", 2001.

[12] Japan Radio Co., "JUE-85 - Inmarsat C for GMDSS", Japan, 2011.

[13] SAILOR, "Inmarsat B - Workshop Manual", Aalborg, Denmark.

[14] Japan Radio Co., “JUE-410F Fleet F77”, Japan, 2003.

[15] ITU Radiocommunication Study Groups, "IALA - Working Document toward a draft new Report Maritime Radiocommunication Systems and Requirements", 2014.

[16] ITU, Report ITU-R M.2287-0, "Automatic identification system VHF data link loading", 2013.

[17] ITU, Report ITU-R M.2231-1, "Use of Appendix 18 to the Radio Regulations for the maritime mobile service", 2014. 